\title{
STRESS AT THE PLACE OF WORK AND COGNITIVE FUNCTIONS AMONG WOMEN PERFORMING INTELLECTUAL WORK DURING PERI- AND POST-MENOPAUSAL PERIOD
}

MARIUSZ GUJSKI ${ }^{1}$, JAROSŁAW PINKAS 2 , TOMASZ JUŃCZYK³, ADRIANNA PAWELCZAK-BARSZCZOWSKA ${ }^{4}$, DOROTA RACZKIEWICZ ${ }^{5}$, ALFRED OWOC ${ }^{4}$, and IWONA BOJAR ${ }^{6}$

${ }^{1}$ Medical University of Warsaw, Warszawa, Poland

Department of Prevention of Environmental Hazards and Allergology

${ }^{2}$ Centre of Postgraduate Medical Education, Warszawa, Poland

School of Public Health

${ }^{3}$ Adam Mickiewicz University in Poznań, Poznań, Poland

Faculty of Educational Studies

${ }^{4}$ Institute of Rural Health in Lublin, Lublin, Poland

Center for Public Health and Health Promotion

${ }^{5}$ Warsaw School of Economics, Warszawa, Poland

Institute of Statistics and Demography

${ }^{6}$ Institute of Rural Health in Lublin, Lublin, Poland

Department for Woman Health

\footnotetext{
Funding: the study was elaborated based on the results of the 3rd stage of the many-year programme "Improvement of safety and work conditions," financed during 2014-2016 within the scope of scientific studies, research and development from the resources of the Ministry of Science and Higher Education/National Centre for Research and Development. Programme coordinator: Central Institute of Labour Protection - National Research Institute. This work was conducted in the Institute of Rural Health, Lublin, Poland, on the basis of the project "Mental and Physical Health of Women in the Perimenopausal and Postmenopausal Period in Terms of Preserving their Ability to Work" (I.P.19). Programme manager: Iwona Bojar, Ph.D.

Received: August 31, 2016. Accepted: January 31, 2017.

Corresponding author: I. Bojar, Institute of Rural Health in Lublin, Department for Woman Health, Jaczewskiego 2, 20-090 Lublin, Poland (e-mail: iwonabojar75@gmail.com).
} 


\begin{abstract}
Objectives: The analysis of the relationship between stress at work and results of cognitive functions amongst women, at peri- and post-menopausal age, performing intellectual work. Material and Methods: The study group included women, aged 45-66 years old, employed as intellectual workers. Research instruments were: the Montreal Cognitive Assessment; computer tests of the CNS Vital Signs; the Subjective Work Characteristics Questionnaire, and a questionnaire designed by the author. The results were statistically analyzed. Results: Nearly a half of respondents experienced high stress at the place of work; $1 / 3$ - on the average level, on a low level - every fifth. The largest number of respondents experienced stress caused by social contacts. Among a half of the women, stress was caused by the lack of awards at work, followed by the lack of support. Slightly fewer of them experienced stress caused by the feeling of psychological load related to the complexity of work or the feeling of uncertainty caused by the organization of work. Every third woman experienced stress due to the sense of responsibility or the lack of control. The smallest number experienced stress caused by physical arduousness, the sense of threat and unpleasant working conditions. The examined women obtained the best results with respect to simple attention, the worst results - with respect to the reaction time. The results concerning the remaining 9 cognitive functions were ranked in the middle of the aforementioned results. The intensity of stress at work and factors which caused this stress, negatively correlated with simple attention of women in the early peri-menopausal period, while positively correlating with the psychomotor and processing speed of women in the late peri-menopausal period. Among the post-menopausal women, negative correlations were observed between the majority of cognitive functions and the intensity of stress at work, and the majority of factors which caused this stress. Conclusions: Cognitive functions of the examined women remained within the range of average evaluations, and were correlated with stress-inducing factors at the place of work. Int J Occup Med Environ Health 2017;30(6):943-961
\end{abstract}

Key words:

Cognitive function, Menopause, Stress at work, Woman health, CNS Vital Signs, Intellectual work

\section{INTRODUCTION}

Menopause is defined as a cessation of ovarian function, that results in permanent amenorrhea, while the menopausal transition - as the period of time from the first variation in menstrual cycle length and elevated follicle-stimulating hormone (FSH) until the final menses [1]. Typical short-term menopausal symptoms are: irregular bleeding, hot flashes, genitourinary symptoms (dryness of vagina, urinary incontinence), depression, as well as decreased libido, headaches, palpitations, chest pain, attention and memory problems. In a long-term perspective post-menopause is related to elevated risk of osteoporosis, cardiovascular disease [2,3], breast cancer and large bowel cancer [4]. Menopausal transition in some cases may lead to psychosocial problems which additionally affect the quality of life of women. There is a general consensus among researchers and practitioners that menopausal transition is the period in life when biological and psychological processes produce new challenges for women, which in turn demand new adaptation strategies from them.

Although women's health and quality of life during menopausal transition have been studied from various perspectives for years [5-12], relatively little is known about the situation of working women with menopausal symptoms. Since most of women remain professionally active in their fifties and sixties, we have to consider the effect of menopause on work capability and work performance. This problem seems to be important also from the perspective of aging societies and speculation on the need of extending the period of work activity. In the context of work, 2 issues related to menopausal transition seem to be of special importance: the effect of stress and menopausal status on cognitive functioning.

\section{Stress and cognitive functions - structural and functional connections}

To simplify the problem, it may be accepted that cognitive functions concern the processes taking place in the brain, related to the receipt, storage, transformation, and further passing of information acquired from the environment. According to Nęcka et al., cognitive processes may be divided into elementary (attention and awareness, cognitive control, perception, memory, memory activities), and complex (thinking and reasoning, problem 
solving, making judgements and decisions, language and speech) [13].

The functional relationship between cognitive processes in a stressful situation and emotions may be analyzed, among others, from the perspective of the construction of the structures of the human brain, primarily regarding the limbic system.

In the context of relationships between emotions and cognition, the limbic system seems to be one of the most important regions of the brain. The functions of its individual structures concern both cognitive and emotional process. Their anatomical vicinity and the afferent and efferent connections among them may explain why emotions and memory, or more broadly - cognitive process - are closely interrelated, and why information is best processed when the level of emotional arousal is optimal.

Studies concerning the effect of stress on individual structures of the limbic system, and the processes for which these structures are responsible, confirm the relationships between stress and cognitive processes, including the ones at the chemical level. The process is extremely complex; however, in the context of the current study it is worth presenting its basic principles. During a stressful situation the secretion of glucocorticosteroids, including cortisol, considerably increases [14]. From the point of view of the aspect of organisms, this is a highly adaptive effect, preparing the body for response to a potentially threatening stimulus. Studies conducted on animals have confirmed that a long-lasting elevation of the level of cortisol exerts a negative effect on activity, as well as on the size of the hippocampus [15].

In human studies, results have been obtained to confirm that cortisol affects the activity of the hippocampus, and consequently, the results of tests engaging cognitive functions [16]. The hippocampus plays an important role in the processes of learning, memory, and attention, and cortisol, commonly called the "stress hormone," impairs its functioning. On-going studies concerning the functioning of the human brain and neurochemical processes within the body preliminarily confirm that stress and cognitive functions are functionally and structurally connected. At the same time, the direction of this relationship indicates that a long-term level of stress arousal exerts a negative effect on consolidation and information processing.

The authors have decided to focus on the problem of occupational stress for several reasons. Firstly, occupational stress appears to be very common. According to studies by the European Agency for Safety and Health at Work (EU-OSHA), $51 \%$ of Poles consider that stress occurs very frequently at their workplace, while $42 \%$ are of the opinion that the control of stress at the workplace is insufficient [17]. Secondly, considering demographic changes, actions will become necessary to allow the maximum prolongation of occupational activity of the elderly, consequently allowing maintenance of their cognitive functions on an optimum level which would permit the performance of occupational tasks. Thirdly, the area of occupational activity generates special risk factors which maximize the probability of the occurrence of stressful situations, i.e., high expectations with respect to the employee, low sense of control, and low social support. Moreover, coping with menopausal symptoms at work seems to be more problematic than at home where women often may adjust their current activity to the level of experienced symptoms. In turn, at work they are expected to maintain high level of performance despite the experienced symptoms which may be a source of additional stress.

\section{Menopause, stress and cognitive functions}

The intensification of some unfavorable changes after menopause, such as cognitive functions disorders, may result from the combination of many factors. During this period, women often experience low mood, nervous tension, or disorders of concentration and memory. Stress related to the life situation of a woman (loss of youth, menopausal symptoms, loss of reproductive abilities), and occupational situation (competition on the part of younger persons), in combination with personality, is the main 
factor triggering serious mood disorders, including depression. This phenomenon is explained by the so-called psychosocial hypothesis. According to this hypothesis, "menopausal susceptibility to depression" is explained by the interaction of 3 types of effects: hormonal mechanism, psychosocial mechanism, and stress [18]. The decrease in the level of estrogens during the menopausal period exerts an effect on neurotransmitters, and consequently, on the limbic system and the hippocampus [19,20], which, according to Greene [18], does not so much lead to the lowering of mood, as impairment of the capability to cope, and increases susceptibility to emotional changes, especially when difficult life situations occur.

Another hypothesis concerning the relationship between stress, cognitive functions and menopause, is based on the knowledge pertaining to the hormonal regulation of the body, especially of prolactin. Firstly, the level of the hormone is higher among women before menopause, as compared to post-menopausal women, and men [21]. Secondly, hyperprolactinemia may cause the decrease in the level of estrogens. In turn, estrogens exert a beneficial effect on cognitive functions, especially in the area of verbal memory and capability to assimilate new concepts [22]. Contemporary literature provides evidence for relationships between the level of prolactin, glucocorticoids and oxytocin on, among others, the intensity of neurogenesis [23], or relationships between the level of prolactin and the results of memory tests or tests concerning cognitive function [24]. Thirdly, the level of prolactin increases as a result of the stress response of the body.

Based on the above mentioned reports it may be presumed that the presence of relationships may be observed between stress, cognitive functions, and menopause.

\section{Objective}

The aim of the study has been to analyze the role of menopause and occupational stress on cognitive functioning of women, at peri- and post-menopausal age, employed as white-collar workers. The relationship between the menopausal status, occupational stress and cognitive functions was analyzed.

\section{MATERIAL AND METHODS}

\section{Study group}

The study was conducted among women aged 45-66 years old at the Institute of Rural Health in Lublin, and covered 300 female white-collar workers. The criteria of exclusion were: education lower than the secondary school, chronic diseases, addictions, diagnosed mental disease in medical history.

All women in the study had the FSH concentration determined. They were divided into 3 groups according to their reproductive status:

- Women within the early peri-menopausal period: menstruating, with the FSH $<20 \mathrm{mlU} / \mathrm{ml}$.

- Women within the late peri-menopausal period: menstruating, with the FSH $\geq 20 \mathrm{mlU} / \mathrm{ml}$.

- Women within the post-menopausal period: not menstruating for at least 12 months.

\section{Research instruments \\ MoCA test (Montreal Cognitive Assessment)}

At the preliminary stage of the study, the MoCA test was applied [25] in order to enroll into the study the women who did not show the symptoms of dementia. The maximum number of scores in this test is 30 ; and the result of 26 or more scores is considered to be normal. The examined women who were included into the further stages of the study had to obtain 26 or higher scores in the MoCA test.

\section{CNS Vital Signs tests}

Assessment of cognitive functions was performed based on the cognitive functions by means of the diagnostic equipment of the CNS Vital Signs (CNS VS) (Polish version), using the software by the CNS Vital Signs. 
The instrument, in the form of a battery of computer tests, was standardized, and was subjected to the full validation procedure. It had had many cultural and language adaptations, including Polish, and the whole examination procedure was therefore performed in Polish. The report from the results, however, was printed in English [26]. The presented cognitive functions were assessed as the following domains: Complex Memory, Verbal Memory, Visual Memory, Psychomotor Speed, Reaction Time, Complex Attention, Cognitive Flexibility, Processing Speed, Executive Function, Simple Attention and Motor Speed.

Calculations were performed using the mean standardized results obtained in tests. The clinical report from the CNS Vital Signs examinations classified the examined women into 5 groups according to the Neurocognitive Index (NCI) and 11 cognitive functions. Standardized results were calculated to classify the examined women into intervals described as: 5 - above average (> 109), 4 - average (90-109), 3 - low average (80-89), 2 - low (70-79), 1 - very low $(<70)$.

The report from the CNS VS test provides the value of the Neurocognitive Index which is computer-calculated in an integrated way based on 5 domains: memory, psychomotor speed, reaction time, attention, and cognitive flexibility.

\section{Subjective Work Characteristics Questionnaire}

The Subjective Work Characteristics Questionnaire [27] is a universal instrument used for the assessment of occupational stress. It is the standardized diagnostic tool with norms for the Polish working population. It consists of 55 items which describe various characteristics of work. The respondent marks the degree of arduousness of each characteristic according to a 5-degree scale. The sum of scores is the indicator of stress burden. The higher the sum of scores, the higher the sense of stress experienced by the respondent. Row scores may be transformed into standard scores (z-scores), and the latter into sten scores, which are subsequently assessed in 3 intervals of results: low (1-3 sten), average (4-7 sten) and high (8-10 sten). In order to determine which factors are most stressful for the respondent, scores are calculated for respective factors: the feeling of psychological load related to the complexity of work, lack of rewards at work, feeling of uncertainty caused by organization of work, social contacts, sense of threat, physical arduous factors, unpleasant work conditions, lack of control, lack of support or sense of responsibility. Raw results calculated for 10 factors are compared with the values in the norm table. If the result obtained by the respondent is equal to or higher than the values specified individually for each factor, it means that a given factor is highly stressful.

\section{Statistical analysis}

The result of statistical analyses of the level of stress at work and cognitive functions was presented for the examined group of women in general, and according to 3 periods of reproductive life.

The analysis of the variance $\mathrm{F}$ test was applied for the purpose of the verification of the hypothesis concerning the equality of the mean standard scores of cognitive functions in 3 periods of reproductive life, the test for stochastic independence $\mathrm{Chi}^{2}$ - for the purpose of the verification of the hypothesis concerning independence between the level of stress at work and 3 periods of reproductive life, and Pearson's correlation coefficient - for the purpose of the investigation of the correlation between the level of stress at work and standard scores of cognitive functions. The significance level was set at 0.05 . In the case of the lack of significant differences among the 3 periods of reproductive life, the results were discussed for the examined group in general.

\section{RESULTS}

A total number of 300 women were examined, including $100(33.33 \%)$ respondents in the early peri-menopausal 
period, $43(14.33 \%)$ - in the late peri-menopausal period, and 157 women $(52.33 \%)$ - in the post-menopausal period. The mean age of respondents was 53.1 \pm 4.8 years old. Based on the study of stressful factors at the place of work using the Subjective Work Characteristics Questionnaire, it was found that nearly a half of the examined women $(47.33 \%)$ experienced a high level of stress at work. Stress on the average level was observed among $34.33 \%$ of the examined women, while on the low level - among $18.33 \%$ (Table 1).

The largest number of women in the study ( $58 \%$ ) experienced stress at work caused by social contacts (Table 2). In a half of the respondents, stress at work was caused by the lack of rewards at work, and in $46.67 \%$ - by the lack of support. A slightly lower percentage of the examined women experienced stress at work caused by the feeling of psychological load related to the complexity of work $(41.33 \%)$ or the feeling of uncertainty caused by the organization of work $(39.33 \%)$. Every third woman in the study experienced stress at work due to the sense of responsibility $(33.33 \%)$ or the lack of control $(32.33 \%)$. The smallest number of respondents experienced stress at work due to physical arduous factors $(15 \%)$, the feeling of threat $(13 \%)$, and unpleasant work conditions $(11 \%)$.

Both the overall level of stress at work and stress caused by the 10 factors which affect it, did not significantly differ among the examined women according to the 3 analyzed periods of reproductive life ( $p>0.05$ ).

The Neurocognitive Index among the examined women was 28-114 standard points, $\mathrm{M} \pm \mathrm{SD}=92.62 \pm 13.05$ points, which indicated an average assessment (Table 3 ).

The examined women obtained the best results with respect to simple attention $(100.76 \pm 11.82$ points, on average), while the worst results - with respect to reaction time $(88.73 \pm 17.04$ points, on average). The results concerning the remaining 9 cognitive functions (from 9296 scores, on average) were ranked in the middle of the above mentioned results.

The indices for cognitive functions did not significantly differ among the examined women in the 3 investigated periods of reproductive life ( $p>0.05)$.

Some significant correlations were observed between cognitive functions of the women in the study and the intensification of stress at (Tables 4-6).

The Neurocognitive Index was significantly negatively correlated with severity of the feeling of threat at work in 3 groups of the examined women: in the early and late peri-menopausal periods as well as in the post-menopausal period. This means that the examined women had the worse NCI the more severe feeling of threat they experienced at work, on average, and vice versa, the better NCI, the less severe feeling of threat at work, on average.

Table 1. Overall level of stress at work among the examined women performing intellectual work in peri- and post-menopausal period

\begin{tabular}{lccc}
\hline & \multicolumn{4}{c}{ Respondents } \\
[n $(\%)]$
\end{tabular}

$\mathrm{Chi}^{2}=3.083 ; \mathrm{p}=0.544$. 
Table 2. Causes of high stress at work among the examined women performing intellectual work in peri- and post-menopausal period

\begin{tabular}{|c|c|c|c|c|c|c|}
\hline \multirow[b]{2}{*}{$\begin{array}{c}\text { Cause of stress } \\
\text { at work }\end{array}$} & \multicolumn{4}{|c|}{$\begin{array}{l}\text { Respondents } \\
{[\mathrm{n}(\%)]}\end{array}$} & \multicolumn{2}{|c|}{$\begin{array}{l}\text { Comparison } \\
\text { of groups }\end{array}$} \\
\hline & $\begin{array}{c}\text { early } \\
\text { peri-menopausal } \\
\text { period } \\
(\mathrm{N}=100)\end{array}$ & $\begin{array}{c}\text { late } \\
\text { peri-menopausal } \\
\text { period } \\
(\mathrm{N}=43)\end{array}$ & $\begin{array}{c}\text { post-menopausal } \\
\text { period } \\
(\mathrm{N}=157)\end{array}$ & $\begin{array}{c}\text { total } \\
(\mathrm{N}=300)\end{array}$ & $\mathrm{Chi}^{2}$ & $\mathrm{p}$ \\
\hline $\begin{array}{l}\text { Feeling of psychological } \\
\text { load related to } \\
\text { the complexity } \\
\text { of work }\end{array}$ & $43(43.00)$ & $16(37.21)$ & $65(41.40)$ & $124(41.33)$ & 0.416 & 0.812 \\
\hline $\begin{array}{l}\text { Lack of rewards } \\
\text { at work }\end{array}$ & $53(53.00)$ & $24(55.81)$ & $73(46.50)$ & $150(50.00)$ & 1.712 & 0.425 \\
\hline $\begin{array}{l}\text { Feeling of uncertainty } \\
\text { caused by the } \\
\text { organization } \\
\text { of work }\end{array}$ & $41(41.00)$ & $20(46.51)$ & $57(36.31)$ & $118(39.33)$ & 1.648 & 0.439 \\
\hline Social contacts & $58(58.00)$ & $26(60.47)$ & $90(57.32)$ & $174(58.00)$ & 0.137 & 0.934 \\
\hline Feeling of threat & $18(18.00)$ & $4(9.30)$ & $17(10.83)$ & $39(13.00)$ & 3.385 & 0.184 \\
\hline $\begin{array}{l}\text { Physical arduous } \\
\text { factors }\end{array}$ & $13(13.00)$ & $6(13.95)$ & $26(16.56)$ & $45(15.00)$ & 0.650 & 0.722 \\
\hline $\begin{array}{l}\text { Unpleasant work } \\
\text { conditions }\end{array}$ & $11(11.00)$ & $3(6.98)$ & $19(12.10)$ & $33(11.00)$ & 0.906 & 0.636 \\
\hline Lack of control & $35(35.00)$ & $14(32.56)$ & $48(30.57)$ & $97(32.33)$ & 0.548 & 0.760 \\
\hline Lack of support & $50(50.00)$ & $18(41.86)$ & $72(45.86)$ & $140(46.67)$ & 0.887 & 0.642 \\
\hline Sense of responsibility & $34(34.00)$ & $16(37.21)$ & $50(31.85)$ & $100(33.33)$ & 0.467 & 0.792 \\
\hline
\end{tabular}

In the case of the examined women who were in the early and late peri-menopausal periods, a few correlations were found between cognitive functions and intensity of stress at work whereas among the post-menopausal women in the study, many of such correlations were observed.

In the case of the examined women in the early perimenopausal period, negative correlations were found as the following (Table 4):

- simple attention with overall level of stress at work and 6 out of 10 factors causing stress at work: feeling of psychological load related to the complexity of work, feeling of uncertainty caused by organization of work, feeling of threat, lack of rewards, control and support;
- complex attention, cognitive flexibility, executive function, motor speed with physical arduous factors with the NCI and 4 out of 10 cognitive functions;

- reaction time and lack of support and feeling of psychological load related to the complexity of work;

- motor speed with the feeling of threat.

In turn, among the examined women in the late perimenopausal period, positive correlations were observed (Table 5):

- psychomotor speed with overall level of stress at work, and intensity of 7 out of 10 factors causing stress at work: feeling of psychological load related to complexity of work, feeling of uncertainty caused by organization 
Table 3. Cognitive functions of the examined women performing intellectual work in peri- and post-menopausal period

\begin{tabular}{|c|c|c|c|c|c|c|}
\hline \multirow{2}{*}{$\begin{array}{l}\text { Cognitive } \\
\text { function test }\end{array}$} & \multicolumn{4}{|c|}{$\begin{array}{l}\text { Standard scores among respondents } \\
\qquad(\mathrm{M} \pm \mathrm{SD})\end{array}$} & \multicolumn{2}{|c|}{$\begin{array}{l}\text { Comparison } \\
\text { of groups }\end{array}$} \\
\hline & $\begin{array}{l}\text { early peri-menopausal } \\
\text { period }\end{array}$ & $\begin{array}{l}\text { late peri-menopausal } \\
\text { period }\end{array}$ & $\begin{array}{l}\text { post-menopausal } \\
\text { period }\end{array}$ & total & $\mathrm{F}$ & $\mathrm{p}$ \\
\hline $\mathrm{NCI}$ & $93.56 \pm 12.96$ & $95.28 \pm 9.29$ & $91.30 \pm 13.87$ & $92.62 \pm 13.05$ & 1.968 & 0.142 \\
\hline Complex memory & $97.50 \pm 14.30$ & $94.53 \pm 16.50$ & $95.13 \pm 15.50$ & $95.83 \pm 15.25$ & 0.920 & 0.400 \\
\hline Verbal memory & $98.97 \pm 12.45$ & $95.47 \pm 17.10$ & $95.86 \pm 15.52$ & $96.84 \pm 14.84$ & 1.562 & 0.211 \\
\hline Visual memory & $97.25 \pm 15.16$ & $96.00 \pm 15.64$ & $96.63 \pm 14.15$ & $96.75 \pm 14.67$ & 0.119 & 0.888 \\
\hline Psychomotor speed & $95.01 \pm 14.73$ & $92.56 \pm 15.13$ & $91.45 \pm 14.31$ & $92.80 \pm 14.61$ & 1.827 & 0.163 \\
\hline Reaction time & $89.78 \pm 16.92$ & $93.47 \pm 11.38$ & $86.76 \pm 18.15$ & $88.73 \pm 17.04$ & 2.938 & 0.054 \\
\hline Complex attention & $93.54 \pm 21.28$ & $98.23 \pm 18.96$ & $93.18 \pm 22.70$ & $94.02 \pm 21.73$ & 0.049 & 0.388 \\
\hline Cognitive flexibility & $92.64 \pm 20.48$ & $95.98 \pm 18.68$ & $91.02 \pm 21.33$ & $92.27 \pm 20.69$ & 0.993 & 0.372 \\
\hline Processing speed & $92.44 \pm 12.71$ & $93.42 \pm 13.72$ & $90.52 \pm 15.62$ & $91.57 \pm 14.44$ & 0.952 & 0.387 \\
\hline Executive function & $93.04 \pm 20.41$ & $96.40 \pm 18.52$ & $91.90 \pm 20.88$ & $92.92 \pm 20.39$ & 0.823 & 0.440 \\
\hline Simple attention & $101.68 \pm 11.05$ & $100.74 \pm 9.15$ & $100.17 \pm 12.91$ & $100.76 \pm 11.82$ & 0.496 & 0.610 \\
\hline Motor speed & $98.10 \pm 15.19$ & $96.33 \pm 12.98$ & $94.39 \pm 14.77$ & $95.91 \pm 14.72$ & 1.968 & 0.142 \\
\hline
\end{tabular}

NCI - Neurocognitive Index; M - mean; SD - standard deviation.

of work, social contacts, sense of responsibility, lack of rewards, control and support;

- processing speed and 3 out of 10 factors causing stress at work: psychological load related to the complexity of work, feeling of uncertainty caused by organization of work and sense of responsibility.

In the case of the post-menopausal women in the study, negative correlations were found as the following (Table 6):

- the NCI with overall level of stress and 9 out of 10 factors causing stress at work (except for physical arduous factors);

- reaction time with overall level of stress and 9 out of 10 factors causing stress at work (except for unpleasant work conditions);

- both complex attention and cognitive flexibility with overall level of stress and 9 out of 10 factors causing stress at work (except for physical arduous factors and unpleasant work conditions);
- executive function with overall level of stress and 5 out of 10 factors causing stress at work: feeling of uncertainty caused by organization of work, feeling of threat, sense of responsibility, lack of control and support;

- processing speed with overall level of stress and 4 out of 10 factors causing stress at work: feeling of uncertainty caused by organization of work, social contacts, feeling of threat and lack of control;

- psychomotor speed with overall level of stress and 4 out of 10 factors causing stress at work: feeling of threat, sense of responsibility, lack of control and support;

- complex and verbal memory, simple attention, motor speed with only one out of 10 factors causing stress at work: complex and verbal memory with unpleasant work conditions, simple attention with feeling of psychological load related to the complexity of work, motor speed with sense of responsibility;

- visual memory, however, did not correlate with any of the factors causing stress at work. 


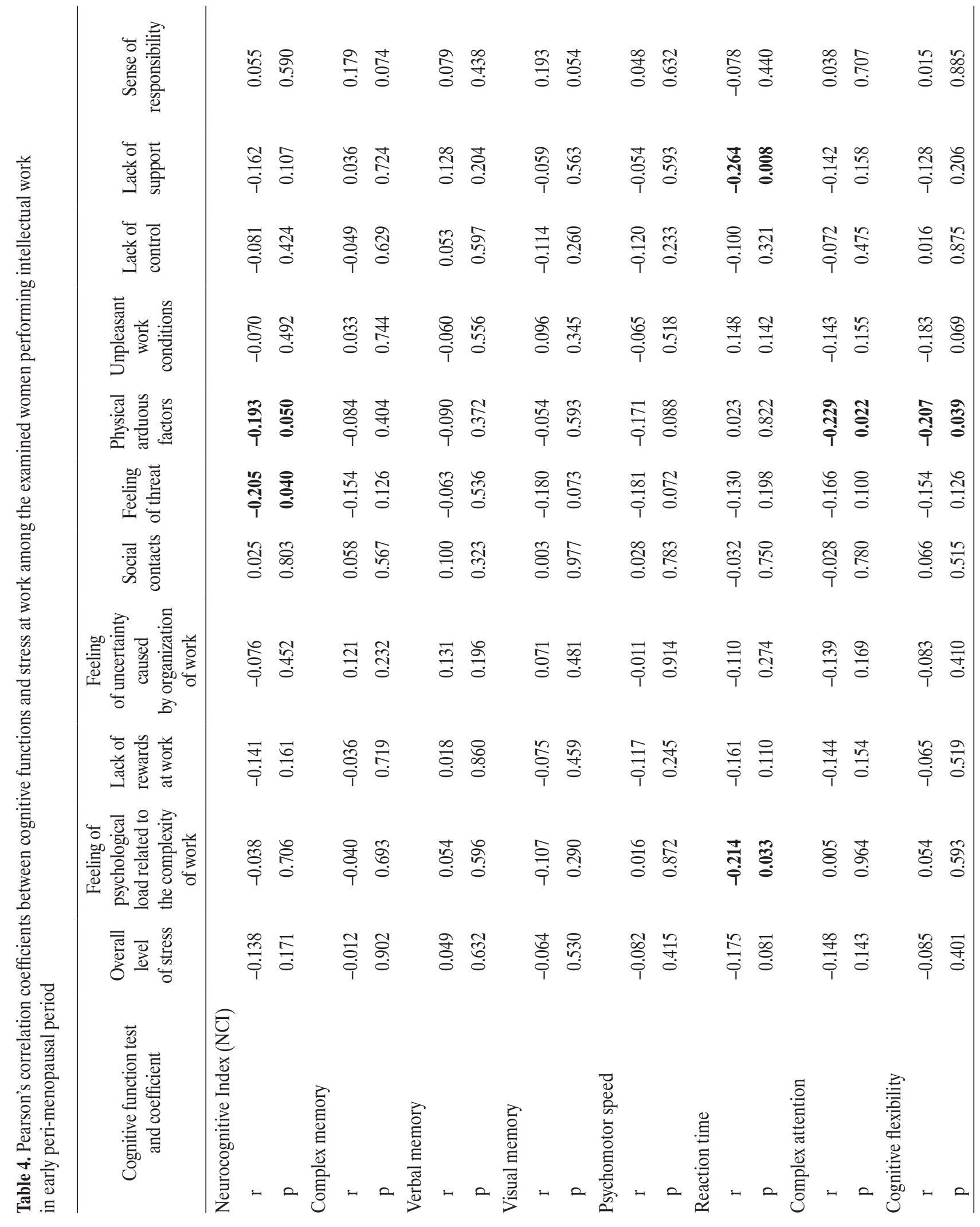




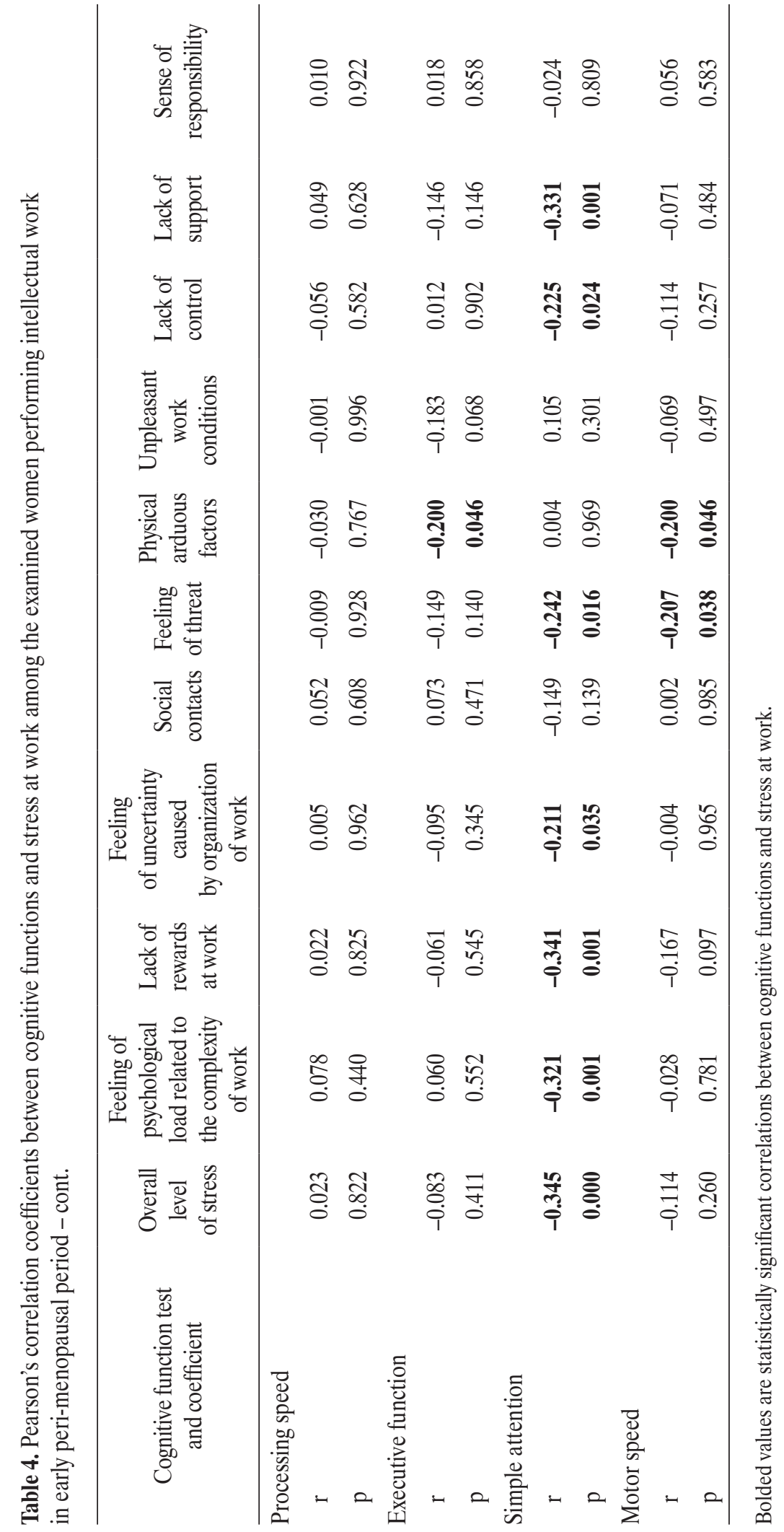




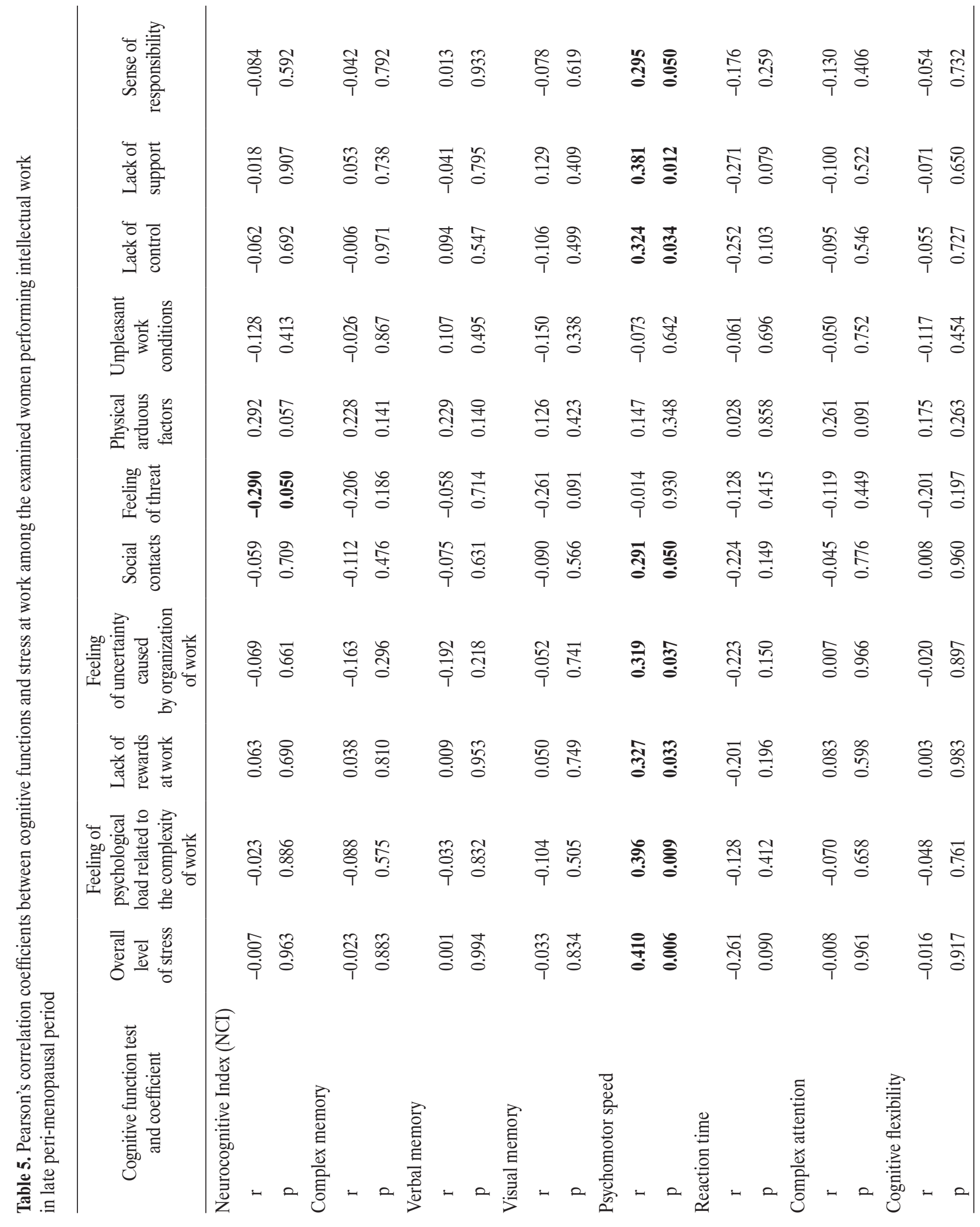




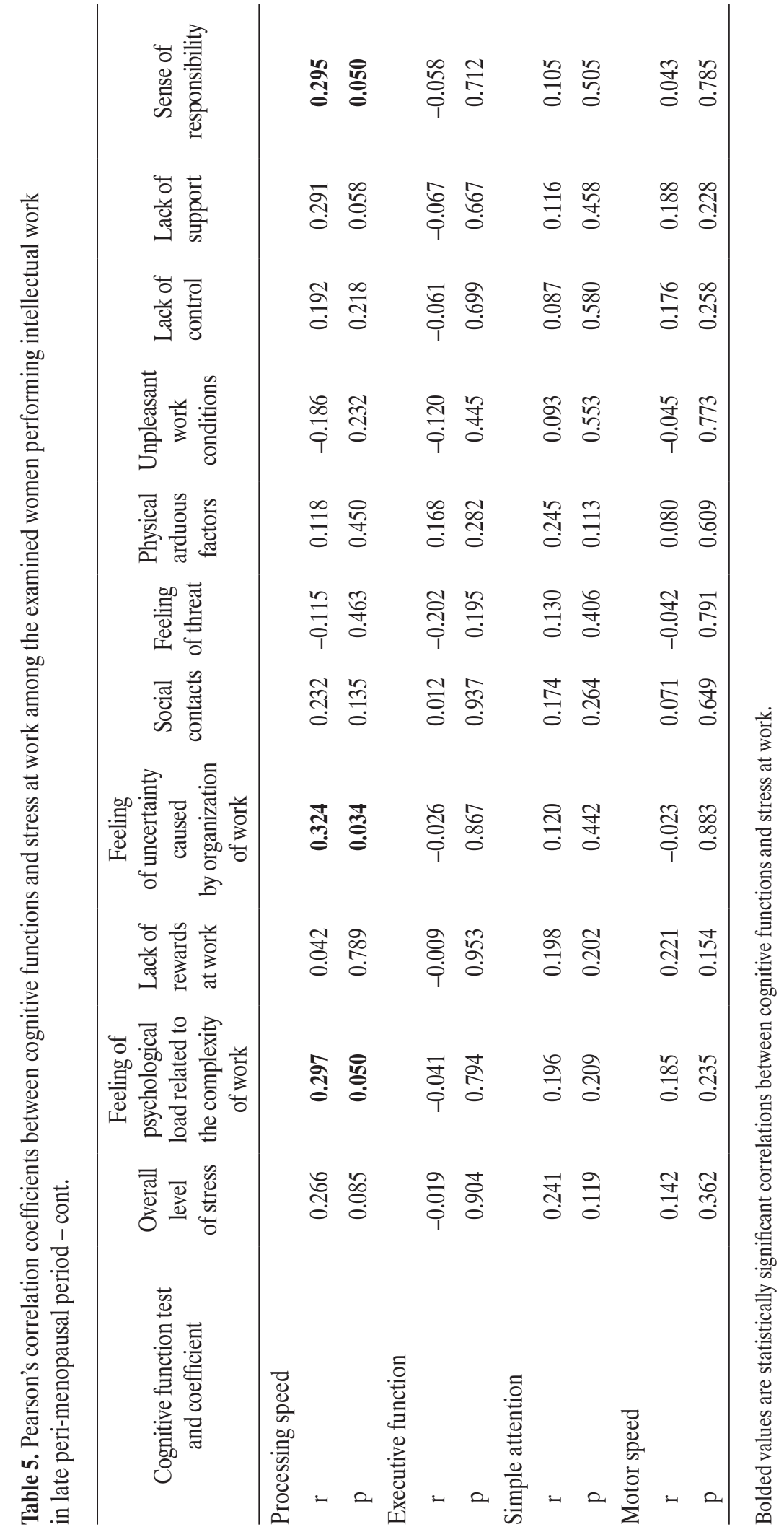




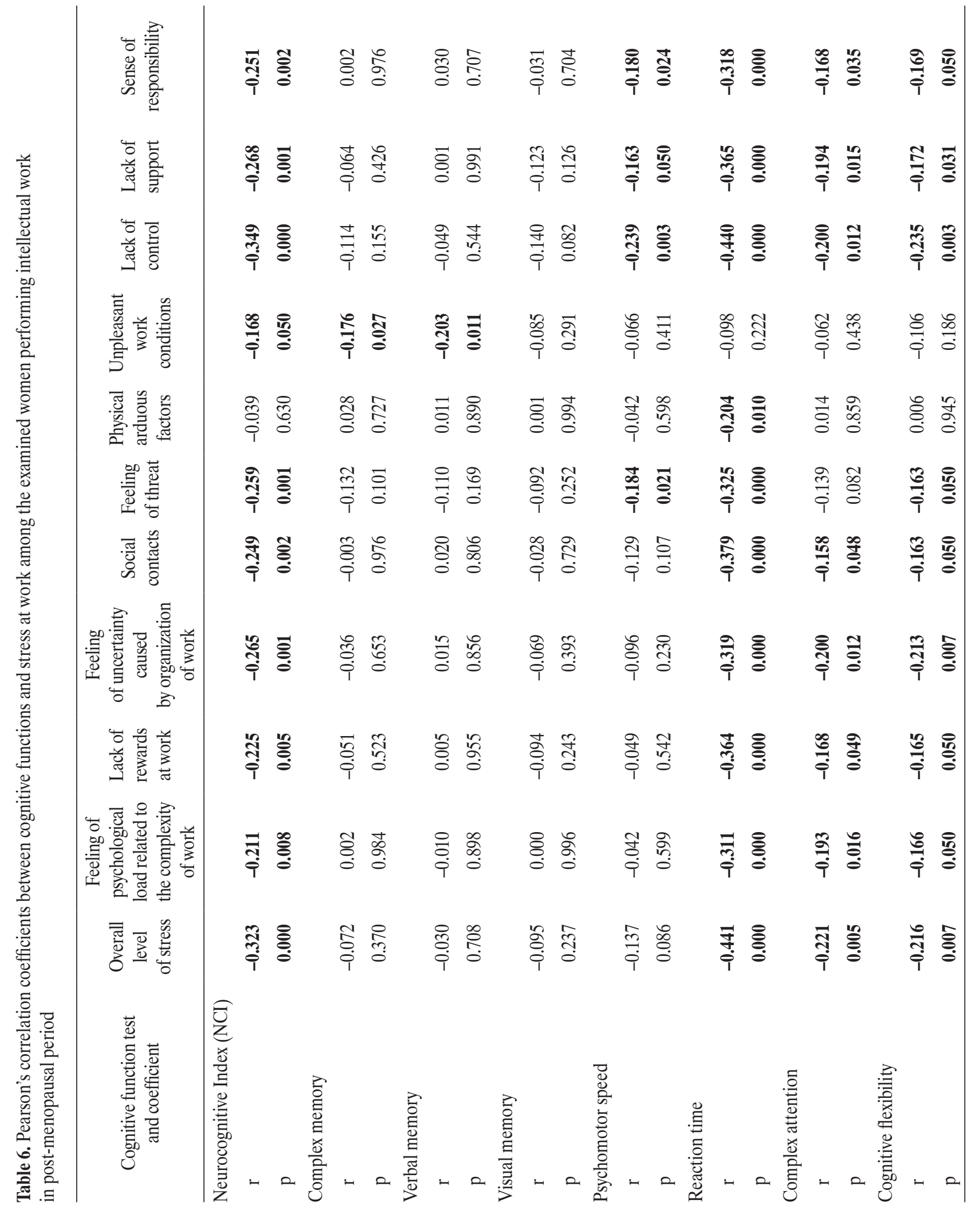




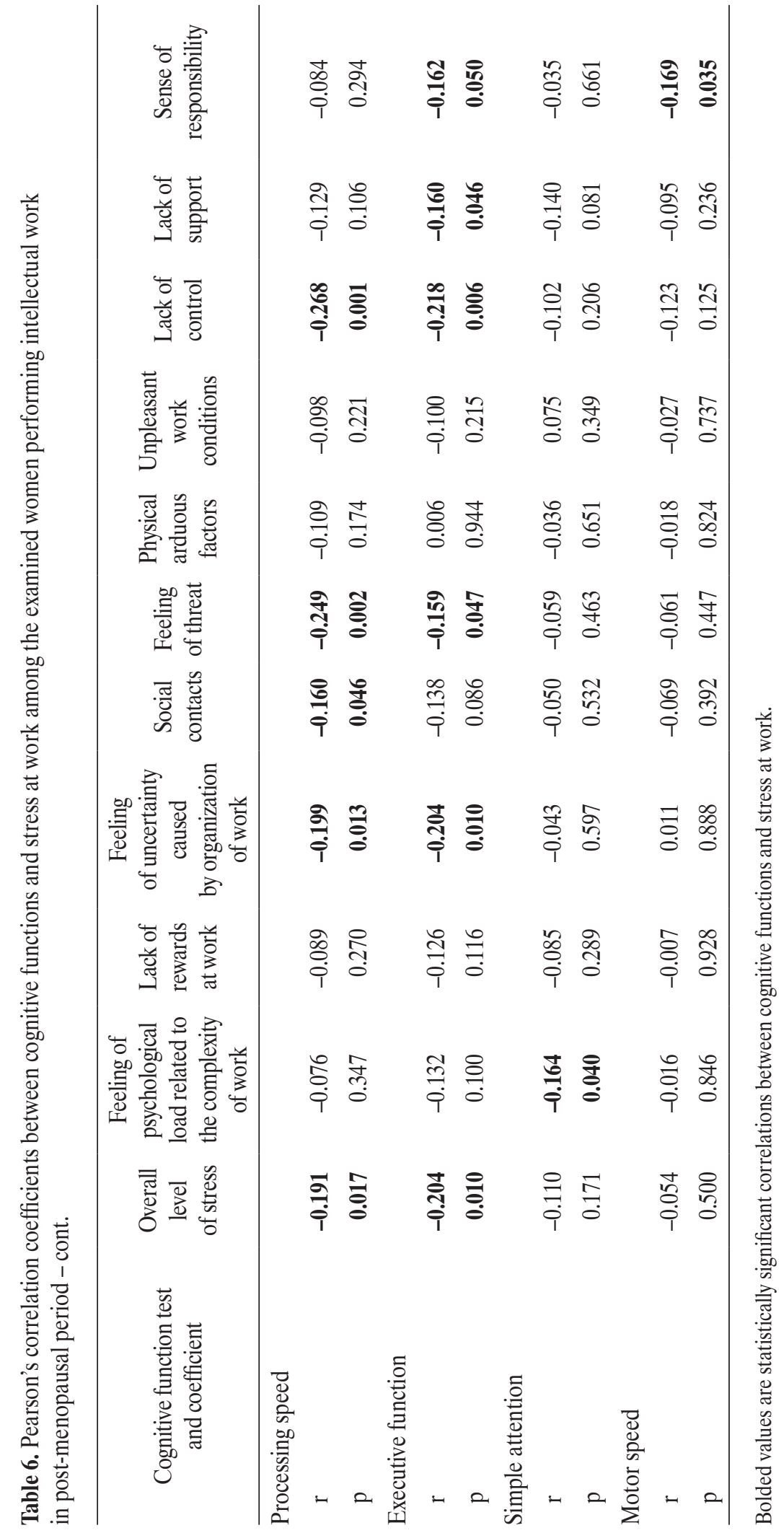




\section{DISCUSSION}

Stress is a multi-dimensional phenomenon, and its effect on the functioning of an individual is ambiguous. Negative consequences of stress appear usually when it is chronic and/or intense.

Stress susceptibility is affected by many factors of biological, environmental and individual nature. As far as women are concerned, there is a sound proof that systems regulating stress and sex hormones act together and even bring about opposite effects in body systems. Estradiol and glucocorticosteroids have balancing effects in an entire body. The estradiol affects brain and cognitive functions in a positive way while glucocorticosteroids affect them negatively. A menopause is associated with an enormous fall in estradiol production. Before the menopause, an estradiol is able to mitigate negative influence of glucocorticosteroids. Taking into account the balancing effects of these hormones, increased responsiveness of hypothalamicpituitary-adrenal axis stemming from aging processes as well as poorer capability to directly mitigate potential negative effects of exposure to glucocorticosteroids due to estradiol shortage, there is a risk of increased and/or more rapid neuronal and cognitive dysfunctions during a postmenopausal period [28].

There are studies which indicate that mitigating injuries and anomalies caused by glucocorticoids through administering exogenous estradiol is one of the benefits of supplementing estradiol during the peri-menopause or shorty after the menopause [29,30]. It is speculated that this mechanism may be responsible for a stronger negative effect of stress through glucocorticosteroids on brain functions related to cognition.

The above mentioned assumptions have been confirmed by many other studies, including those of neurobiological nature. It has been found that in the case of rats subjected to a long-term effect of intensive stress, proliferation of the cells of the hippocampus and the increase in the level of expression of fibroblast growth factor 2 (FGF2) are reported. As a result, upon the lapse of 2 weeks, i.e., the time indispensable for the maturation of newly-developed nerve cells, the rats showed improved performance in the tasks engaging memory. The labelling technique allowed for the presumption that for the performance of the task, the nerve cells which developed as a result of stress were engaged [31]. This experiment enabled a better understanding of the adaptivity to a short-term stressful reaction.

The negative correlations between stress at work and cognitive functions are also confirmed by the available studies. In 2014, the results of studies were published, that had been conducted among 152 British nurses. This occupation is considered to be highly stressful. The results confirmed the correlation between the level of stress and such aspects of cognitive functioning as: the speed of information processing or the number of mistakes committed. Even more so, the studies also revealed the effect of this functioning on the direct actions performed by the nurses - those who had worse cognitive parameters more often called an ambulance or after conversation took longer to complete documents [32].

In our study it was decided to conduct investigations in the homogeneous group of female white-collar workers in the peri- and post-menopausal period. This is definitely the strength of the study, because this is the group in which even slight cognitive disorders may affect the effectiveness and quality of work. Nearly a half of the examined women experienced a high level of stress at the workplace. Stress at work on the average level was observed in every third respondent. The largest number of women experienced stress at work caused by social contacts. Many significant correlations were observed between cognitive functions of the examined women and the intensity of stress at their work. It is an interesting fact that in the early peri-menopausal period and after the menopause these were negative correlations, which meant that the lower the cognitive functions of the examined women, the higher the stress 
they experienced whereas in the group of women in the late peri-menopausal period, positive correlations were noted, which meant that the better their cognitive functions, the higher the stress they experienced at work. This phenomenon should certainly be analyzed in further studies considering changes in the levels of sex hormones during this period of life.

One of the variables analyzed in the presented study was the women's age in the context of menopausal processes. The analysis of results did not reveal any significant correlations with cognitive functions and stress; however, the available studies show that this area is important for scientific verification. The available results indicate, among others, that the differences in the performance of cognitive tasks are observed after a stressful event among women in the follicular phase, and those in the luteal phase of the menstruation cycle [33], or differences in emotional memory among women in the luteal phase of the menstruation cycle, and those who use hormonal contraception [34]. Here, the importance of hormones seems to be the key issue, which may certainly be reflected during the peri-menopausal period and after the menopause.

While analyzing the effect of stress on cognitive functions, differences are revealed primarily between the importance of long-term and short-term stress. The former may be considered as harmful, while short-lasting stress occurs to be of developmental importance. The development of neuroscience allows for the perception of increasingly more precise correlations among various variables, important for the phenomena, such as the effect of hormones. In this context, it may be presumed that the problems undertaken in the presented study, related to stress, cognitive functions and age of women, require further, more comprehensive studies.

It is noteworthy that the results obtained in this study confirm that stress, understood as an overall result, or one of the factors evoking stress, negatively correlates with 11 out of the 12 cognitive functions examined. Only "motor speed" is not related with stress. An inspirational explanation of this phenomenon may arise from the studies conducted on rats in 2014, in which induced stress affected locomotor activity of the rats according to the environment, while an inhibitory effect of stress was perceived exclusively in the case of rats living in "multifunctional cages" [17]. Perhaps the relationship between "motor speed" and the level of stress among the examined women has not been perceived, because the diagnostic tests of the CNS Vital Signs battery did not require from the respondents the application of complex behavioral strategies. This hypothesis is even more probable because the available literature concerning studies on rats indicates that, basically, there exists a correlation between motor functions and stress [35].

\section{CONCLUSIONS}

The examined women in the peri- and post-menopausal periods obtained the best results with respect to simple attention whereas the worst results - reaction time.

The majority of women in the study experienced a high or average intensity of stress at work. The largest number of the examined women experienced stress at work related to social contacts or the lack of rewards.

The results of cognitive functions and the intensity of stress at work and factors which caused this stress did not significantly differ among women in the analyzed peri- and post-menopausal periods.

Cognitive functions of the examined women correlated in different ways with the intensity of stress at work. In the early peri-menopausal period, simple attention negatively correlated with the intensity of stress at work and factors which caused this stress. In the late peri-menopausal period, psychomotor and processing speed of women positively correlated with stress. In the group of women in the post-menopausal period, negative correlations were observed between the majority of cognitive functions and the intensity of stress at work, and the majority of factors which caused this stress. 


\section{REFERENCES}

1. Avis NE, Crawford S, Johannes CB. Menopause. In: Wingood GM, DiClemente RJ, editors. Handbook of women's sexual and reproductive health. New York: Kluwer Academic/ Plenum Publishers; 2002. p. 367-91.

2. Black DM, Rosen CJ. Postmenopausal Osteoporosis. N Engl J Med. 2016;374(3):254-62, https://doi.org/10.1056/NEJMcp1513724.

3. International Menopause Society Consensus Statement. Aging, menopause, cardiovascular disease and HRT. Climacteric. 2009;12:368-77, https://doi.org/10.1080/1369713090 3195606 .

4. Kopenhager T, Guidozzi F. Working women and the menopause. Climacteric. 2015;18:372-5, https://doi.org/10.3109/13 697137.2015.1020483.

5. Matthews KA, Bromberger JT. Does the menopausal transition affect health-related quality of life? Am J Med. 2005;118(12):25-36, https://doi.org/10.1016/j.amjmed.2005. 09.032.

6. Woods NF, Mitchell ES. Symptoms during the perimenopause: Prevalence, severity, trajectory, and significance in women's lives. Am J Med. 2005;118(12):1405-6, https://doi. org/10.1016/j.amjmed.2005.10.008.

7. Low L-F, Anstey KJ, Jorm AF, Rodgers B, Christensen H. Reproductive period and cognitive function in a representative sample of naturally postmenopausal women aged 60-64 years. Climacteric. 2005;8:380-9, https://doi.org/10. 1080/13697130500345240.

8. Avis NE, Crawford SL, Greendale G, Bromberger JT, Everson-Rose SA, Gold EB, et al. Duration of menopausal vasomotor symptoms over the menopause transition. JAMA Intern Med. 2015;175(4):531-9, https://doi.org/10.1001/jamainternmed.2014.8063.

9. Bojar I, Wierzbińska-Stępniak A, Witczak M, Raczkiewicz D, Owoc A. Are cognitive functions in post-menopausal women related with the contents of macro- and micro-components in the diet? Ann Agric Environ Med. 2015;22(1):178-84, https:// doi.org/10.5604/12321966.1141391.
10. Baumgart M, Snyder HM, Carrillo MC, Fazio S, Kim H, Johns H. Summary of the evidence on modifiable risk factors for cognitive decline and dementia: A population-based perspective. Alzheimers Dement. 2015;11(6):718-26, https:// doi.org/10.1016/j.jalz.2015.05.016.

11. Korczyn AD, Halperin I. Depression and dementia. J Neurol Sci. 2009;283(1):139-42, https://doi.org/10.1016/ j.jns.2009.02.346.

12. Tsolaki M, Papaliagkas V, Kounti F, Messini C, Boziki M, Anogianakis G, et al. Severely stressful events and dementia: A study of an elderly Greek demented population. Psychiatry Res. 2010;176(1):51-4, https://doi.org/10.1016/j.psychres.2009.06.001.

13. Nęcka E, Orzechowski J, Szymura B. [Cognitive psychology]. Warszawa: Academica Wydawnictwo SWPS, Wydawnictwo Naukowe PWN; 2008. Polish.

14. Krauzowicz J. [Neurocognitivistics in pathology and health 2011-2013. Stress - A constructor or destructor of cognitive processes?]. Szczecin: Pomorski Uniwersytet Medyczny w Szczecinie; 2014. p. 84-92. Polish.

15. Ohl F, Michaelis T, Vollmann-Honsdorf GK, Kirschbaum C, Fuchs E. Effect of chronic psychosocial stress and long-term cortisol treatment on hippocampus-mediated memory and hippocampal volume: A pilot-study in tree shrews. Psychoneuroendocrinology. 1999;25(2000):357-63, https://doi.org/ 10.1016/S0306-4530(99)00062-1.

16. Khalili-Mahani N, Dedovi K, Engert V, Pruessner M, Pruessner JC. Hippocampal activation during a cognitive task is associated with subsequent neuroendocrine and cognitive responses to psychological stress. Hippocampus. 2010;20:323-34, https://doi.org/10.1002/hipo.20623.

17. European Agency for Safety and Health at Work [Internet]. The Agency; 2017 [cited 2017 Jan 31]. Psychosocial risks and stress at work. Available from: https://osha.europa.eu/en/ themes/psychosocial-risks-and-stress.

18. Greene JG. The psychosocial vulnerability model of the menopause. In: Aso T, Yanaihara T, Fujimoto S, editors. The menopause at the millenium. The proceedings of the 9th 
International Menopause Society World Congress on the Menopause. New York: The Parthenon Publishing Group; 2000. p. 536-9.

19. Bielawska-Batorowicz E. [Concepts of menopause. Part III psychopathological approach]. Prz Menopauz. 2005;4(5): 24-31. Polish.

20. Douma SL, Husband C, O'Donnell ME, Barwin BN, Woodend AK. Estrogen-related mood disorders: Reproductive life cycle factors. ANS Adv Nurs Sci. 2005;28(4):364-75, https://doi.org/10.1097/00012272-200510000-00008.

21. Bojar I, Raczkiewicz D, Wdowiak A, Owoc A. [Level of prolactin and apolipoprotein E gene polymorphism and cognitive functions in postmenopausal women]. Ginekol Pol. 2014;85:131-9. Polish.

22. Ziołkowska A, Rzewuska M. [Neuroleptic-induced hyperprolactinemia - literature review]. Farmakoter Psychiatr Neurol. 2001;1:72-85. Polish.

23. Castanho TC, Moreira PS, Portugal-Nunes C, Novais A, Costa PS, Palha JA, et al. The role of sex and sex-related hormones in cognition, mood and well-being in older men and women. Biol Psychol. 2014;103:158-66, https://doi.org/ 10.1016/j.biopsycho.2014.08.015.

24. Henry J, Sherwin B. Hormones and cognitive functioning during late pregnancy and postpartum: A longitudinal study. Behav Neurosci. 2012;126:73-85, https://doi.org/10.1037/ a0025540.

25. Magierska J, Magierski R, Fendler W, Kłoszewska I, Sobów TM. Clinical application of the Polish adaptation of the Montreal Cognitive Assessment (MoCA) test in screening for cognitive impairment. Neurol Neurochir Pol. 2012;46:130-9, https://doi.org/10.5114/ninp.2012.28255.

26. Gualiteri CT, Johnson LG. Reliability and validity of computerized neurocognitive test battery, CNS Vital Signs. Arch Clin Neuropsychol. 2006;21:623-43, https://doi. org/10.1016/j.acn.2006.05.007.

27. Dudek B, Waszkowska M, Hanke W. [Protection of the health of workers against negative effect of occupational stress]. Łódź: Instytut Medycyny Pracy; 1999. Polish.
28. Ycaza Herrera A, Mather M. Actions and interactions of estradiol and glucocorticoids in cognition and the brain: Implications for aging women. Neurosci Biobehav Rev. 2015;55:36-52, https://doi.org/10.1016/j.neubiorev.2015.04.005.

29. Barha CK, Galea LA. The hormone therapy, Premarin, impairs hippocampus-dependent spatial learning and memory and reduces activation of new granule neurons in response to memory in female rats. Neurobiol Aging. 2013;34(3):986-1004, https://doi.org/10.1016/j.neurobiol aging.2012.07.009.

30. McClure RE, Barha CK, Galea LA. 17ß-Estradiol, but not estrone, increases the survival and activation of new neurons in the hippocampus in response to spatial memory in adult female rats. Horm Behav. 2013;63(1):144-57, https://doi. org/10.1016/j.yhbeh.2012.09.011.

31. Kirby ED, Muroy SE, Sun WG, Covarrubias D, Leong MJ, Barchas LA, et al. Acute stress enhances adult rat hippocampal neurogenesis and activation of newborn neurons via secreted astrocytic FGF2. eLife. 2013;2:e00362, https://doi. org/10.7554/eLife.00362.

32. Allan JL, Farquharson B, Johnston DW, Jones MC, Choudhary CJ, Johnston M. Stress in telephone helpline nurses is associated with failures of concentration, attention and memory, and with more conservative referral decisions. Br J Psychol. 2014;105:200-13, https://doi.org/10.1111/ bjop.12030.

33. Zoladz PR, Peters DM, Cadle CE, Kalchik AE, Aufdenkampe RL, Dailey AM, et al. Post-learning stress enhances long-term memory and differentially influences memory in females depending on menstrual stage. Acta Psychol. 2015;160:127-33, https://doi.org/10.1016/j.actpsy. 2015.07.008.

34. Nielsen SE, Ahmed I, Cahill L. Post-learning stress differentially affects aemory for emotional gist and detail in naturally cycling women and women on hormonal contraceptives. Behav Neurosci. 2014;128(4):482-93, https://doi.org/10.1037/ a0036687. 
35. Faraji J, Soltanpour N, Jafari SY, Moeeini R, Pakdel S, Moharreri A, et al. Stress inhibits psychomotor performance differently in simple and complex open field environments. Horm Behav. 2014;65(1):66-75, https://doi.org/10.1016/j.yhbeh.2013.11.007.

This work is available in Open Access model and licensed under a Creative Commons Attribution-NonCommercial 3.0 Poland License - http://creativecommons.org/ licenses/by-nc/3.0/pl/deed.en. 